\title{
Parameters predicting lymph node metastasis in patients with superficial esophageal squamous cell carcinoma
}

\author{
Liyan Xue ${ }^{1}$, Liqun Ren ${ }^{1,2}$, Shuangmei Zou ${ }^{1}$, Ling Shan ${ }^{1}$, Xiuyun Liu ${ }^{1}$, Yongqiang Xie ${ }^{1}$, \\ Yueming Zhang ${ }^{3}$, Jun Lu ${ }^{1,4}$, Dongmei Lin ${ }^{1}$, Sanford M Dawsey ${ }^{5}$, Guiqi Wang ${ }^{3}$ and Ning Lu ${ }^{1}$ \\ ${ }^{1}$ Department of Pathology, Peking Union Medical College, Chinese Academy of Medical Sciences, Beijing, \\ China; ${ }^{2}$ Department of Pathology, Chengde Medical College, Chengde, China; ${ }^{3}$ Department of Endoscopy, \\ Cancer Institute (Hospital), Peking Union Medical College, Chinese Academy of Medical Sciences, Beijing, \\ China; ${ }^{4}$ Department of Pathology, Beijing Chaoyang Hospital, Beijing, China and ${ }^{5}$ Nutritional Epidemiology \\ Branch, Division of Cancer Epidemiology and Genetics, National Cancer Institute, Bethesda, MD, USA
}

\begin{abstract}
Endoscopic resection is a less invasive treatment than esophagectomy for superficial esophageal squamous cell carcinoma, but patients with lymph node metastasis need additional treatment after endoscopic resection. The purpose of this study was to establish a set of indicators to identify superficial esophageal squamous cell carcinoma patients at a high risk of metastasis. In all, 271 superficial esophageal squamous cell carcinoma esophagectomy cases were reviewed retrospectively. The relationships between clinicopathological parameters and immunohistochemical findings (p53, cyclin D1, EGFR and VEGF) on tissue microarrays, on the one hand, and lymph node metastasis were assessed by univariate and multivariate logistic regression analyses. Patients with intraluminal masses and ulcerated masses had a high risk of lymph node metastasis. Patients with superficial esophageal squamous cell carcinoma (1) thinner than $1200 \mu \mathrm{m}$; (2) confined to the mucosa; (3) with submucosal invasion $<250 \mu \mathrm{m}$; (4) with submucosal invasion $\geq 250 \mu \mathrm{m}$ but with negative VEGF expression and well/moderately differentiated or basaloid histology; or (5) with submucosal invasion $\geq 250 \mu \mathrm{m}$ but with weak VEGF expression and well-differentiated histology had almost no risk of lymph node metastasis. We recommend endoscopic resection for all erosive, papillary and plaque-like superficial esophageal squamous cell carcinomas where endoscopic resection is clinically feasible, and esophagectomy for all other erosive, papillary and plaque-like cases and all intraluminal masses and ulcerated tumors. No additional treatment is needed for endoscopic resection cases with superficial esophageal squamous cell carcinoma (1) thinner than $1200 \mu \mathrm{m}$; (2) confined to the mucosa; (3) with submucosal invasion $<250 \mu \mathrm{m}$; (4) with submucosal invasion $\geq 250 \mu \mathrm{m}$ but with negative VEGF expression and well/moderately differentiated or basaloid histology; or (5) with submucosal invasion $\geq 250 \mu \mathrm{m}$ but with weak VEGF expression and well-differentiated histology. These clinical and pathological criteria should enable more accurate selection of patients for these procedures. Modern Pathology (2012) 25, 1364-1377; doi:10.1038/modpathol.2012.89; published online 25 May 2012
\end{abstract}

Keywords: endoscopic resection; esophageal cancer; lymph node metastasis; superficial cancer; squamous cell carcinoma

Esophageal squamous cell carcinoma is one of the most common malignancies worldwide, especially in East Asia. Patients with superficial esophageal

Correspondence: Dr N Lu, MD, Department of Pathology, Cancer Institute (Hospital), Peking Union Medical College, Chinese Academy of Medical Sciences, Beijing 100021, China.

E-mail: nlu03@126.com

Received 5 December 2011; revised 28 January 2012; accepted 28 January 2012; published online 25 May 2012 squamous cell carcinoma, confined to the mucosa or submucosa without lymph node metastasis, have a significantly more favorable clinical course, compared with patients with advanced esophageal squamous cell carcinoma.

In recent years, endoscopic resection, including endoscopic mucosal resection, multiband mucosectomy and endoscopic submucosal dissection, has been developed, with excellent results for the treatment of superficial esophageal squamous cell 
carcinoma and precursor lesions. ${ }^{1-4}$ Endoscopic resection is safe, easy, and esophagus preserving, with many fewer postoperative complications than esophagectomy. However, patients with lymph node metastasis should not be candidates for endoscopic resection. They need additional esophagectomy or radiochemotherapy if they are treated with endoscopic resection. To optimize the success of endoscopic resection, it is important to establish good indicators to identify patients at high risk of metastasis, to determine which patients are suitable for endoscopic resection and which patients need additional esophagectomy or radiochemotherapy after endoscopic resection.

Previous studies have reported that several clinicopathological parameters, including tumor size (length), macroscopic shape, depth of invasion, tumor differentiation and angiolymphatic invasion may be predictors of lymph node metastasis in superficial esophageal squamous cell carcinoma. ${ }^{5-14}$

Superficial esophageal squamous cell carcinomas are divided into five levels, based on the greatest depth of tumor invasion: m2 (lamina propria), m3 (muscularis mucosae), sm1, sm2 and sm3 (superficial, middle and deep thirds of the submucosa, respectively). ${ }^{15}$ Only lesions no deeper than sm1 are considered suitable for endoscopic resection. ${ }^{1,15}$ But in endoscopic resections, the full thickness of the submucosal tissue is not removed, so it is difficult to classify the depth of tumor invasion as sm1, sm2 or sm3 in endoscopic resection specimens. However, it is easy to record some depth measurements, including total tumor thickness and the thickness of submucosal invasion, using an ocular micrometer.

Molecular biomarkers will also be clinically useful if they can help to predict metastasis. Immunohistochemistry is a simple, reproducible way to assess the expression of oncogenic factors in paraffin-embedded cancer tissues. P53, cyclin D1, EGFR and VEGF are the most promising prognostic immunohistochemical markers in many cancers, but few studies have evaluated these markers for predicting metastasis in superficial esophageal squamous cell carcinoma.

Most of the studies of clinicopathological and/or immunohistochemical features predicting metastasis of superficial esophageal squamous cell carcinoma have come from Japan. ${ }^{5,7,9-12,14}$ In comparison, very few reports have come from other countries, including China. ${ }^{6,8,16,17}$ It should be noted that significant differences in diagnostic criteria for esophageal squamous cell carcinoma exist between Japanese and Western pathologists, ${ }^{18,19}$ and these differences may contribute to the relatively high incidence and good prognosis of superficial esophageal squamous cell carcinoma in Japan. In China, western diagnostic criteria are more commonly used.

In this study, we examined 271 Chinese superficial esophageal squamous cell carcinomas to investigate the value of standard clinicopathological parameters, certain microscopic measurements, and the above four immunohistochemical biomarkers in predicting metastasis of superficial esophageal squamous cell carcinoma, in order to provide criteria for optimizing individual therapy.

\section{Materials and methods}

\section{Patients}

In all, 271 superficial esophageal squamous cell carcinomas received esophagectomy, without preoperative radiochemotherapy, at the Cancer Institute (Hospital), Peking Union Medical College, Chinese Academy of Medical Sciences between February 1990 and January 2004. This study was approved by the Institutional Review Board of Cancer Institute (Hospital), Peking Union Medical College, Chinese Academy of Medical Sciences, and interpretation of anonymized data was exempted from review by the Office of Human Subject Review of the NIH.

\section{Macroscopic Tumor Types}

We defined the cases into six macroscopic tumor types, based on the criteria of macroscopic shapes used widely in China $^{20}$ and used by some groups in other countries. ${ }^{16,21}$

\section{Occult type}

The lesion is smooth and flat, neither elevated nor depressed. It is difficult to be distinguished with white light endoscopy, but can be found as an unstained lesion after Lugol's iodine staining (Paris classification $0-$ IIb).

\section{Erosive type}

The mucosa is slightly elevated or depressed, or coarse, neither protruding nor ulcerated. The lesion is map-shaped, with irregular margins (Paris classifications 0-IIa, 0-IIb, 0-IIc or 0-IIa + IIc).

\section{Papillary type}

The lesion looks like a polyp, either sessile or pedunculate, with the largest diameter $<3 \mathrm{~cm}$ (Paris classification $0-\mathrm{Ip}$ ).

Plaque-like type

The lesion is elevated, and sometimes combined with slight depressions (Paris classifications 0-Is or 0-IIa).

\section{Ulcerative type}

The lesion has a prominent ulcer in the center, commonly combined with elevated ridges around the edges (Paris classifications $0-$ III or $0-\mathrm{III}+\mathrm{I}$ ). 
Intraluminal mass (Fungating) type

The lesion looks like a mushroom or a big polyp, commonly pedunculated, with the largest diameter $>3 \mathrm{~cm}$ (Paris classification 0-Ip). ${ }^{22}$

\section{Standard Histopathological Variables}

All standard and measured histopathological variables and all immunohistochemistry slides were first reviewed and graded independently by three authors (LX, LR and SZ), and then discordant cases were reviewed jointly until a consensus was reached. When a patient had multicentric esophageal carcinomas, the histopathological factors for the lesion with the greatest invasion depth were evaluated.

Maximum depth of invasion was classified into five levels: $\mathrm{m} 2, \mathrm{~m} 3, \mathrm{sm} 1, \mathrm{sm} 2$ or $\mathrm{sm} 3$, as described above. ${ }^{15}$ Tumor differentiation was classified as well differentiated, moderately differentiated, poorly differentiated, basaloid squamous cell carcinoma or spindle cell/sarcomatoid squamous cell carcinoma according to the WHO criteria. ${ }^{23}$ Multicentric invasive esophageal cancer lesions, angiolymphatic invasion and glandular involvement by high-grade dysplasia/carcinoma-in-situ were categorized as present or absent.

\section{Measured Histopathological Variables}

At the site where carcinoma invasion was the most remarkable, tumor thickness from the surface to the base (the invasive front of cancer nests) and submucosal invasion thickness from the bottom of muscularis mucosae to the base of cancer nests were measured with an ocular micrometer (Leica, Germany). In specimens where the muscularis mucosae was disrupted by ulceration or tumor invasion, the muscularis mucosae level was estimated by drawing a line to connect the remaining muscularis mucosae. Submucosal invasion thickness was only measured in submucosal cases, and was defined as 0 in mucosal cases. The diameter of the largest invasive lesion was also measured microscopically.

\section{Tissue Microarray Construction}

Seventy-five cases were unsuitable for tissue microarray construction (insufficient cancer tissue remaining in the blocks) or immunohistochemistry (the original blocks were damaged). Tissue microarrays were constructed from two 0.6-mm cores of tumor tissue and two $0.6-\mathrm{mm}$ cores of normal epithelium from each case of the other 196 superficial esophageal squamous cell carcinomas using a Manual Tissue Arrayer (MTA-1, Beecher Instruments, Silver Spring, MD, USA).

\section{Immunohistochemistry}

The MaxvisionTMHRP-polymer anti-mouse/rabbit method was used for immunohistochemical staining. Antigen retrieval was performed by pressure oven (1.5 min) in EDTA ( $\mathrm{pH} \mathrm{9.0)} \mathrm{for} \mathrm{VEGF} \mathrm{or} \mathrm{in} 0.01 \mathrm{M}$ sodium citrate buffer $(\mathrm{pH}$ 6.0) for the other antibodies. The primary antibodies (p53 and VEGF working solution from Maxim Biological Technology, Fuzhou, China; cyclin D1 and EGFR working solution from Zhong Shan-Golden Bridge Biological Technology, Beijing, China) were incubated for $1 \mathrm{~h}$ at room temperature. The bound antibody was then detected with goat anti-mouse/rabbit IgG HRP-polymer (Maxim Biological Technology) for 15 min. 3,3'Diaminobenzidine was used as the chromogen. Slides were lightly counterstained with hematoxylin.

Only nuclear staining of p53 and cyclin D1, only membrane staining of EGFR, and either membrane or cytoplasmic staining of VEGF were classified as positive.

The criteria for scoring p53, cyclin D1 and VEGF were as follows. First, the intensity was graded as follows: 0 , negative; 1 , weak; 2 , moderate; 3 , strong. Second, the proportion of positive tumor cells was graded: $0,<5 \% ; 1,5-25 \% ; 2,26-50 \%$; 3 , $51-75 \% ; 4,>75 \%$. A final score was derived by multiplication of these two primary scores. Final scores of 0-4 were defined as 'negative expression' $(-)$; scores of 5-8 as 'weakly positive expression' $(+)$ and scores of 9-12 as 'strongly positive expression' $(++) .^{24}$

The criteria for scoring EGFR were as follows: negative or equivocal $(-)$, no discernible staining or definite cytoplasmic staining, with no or equivocal discontinuous membrane staining; weakly positive $(+)$, unequivocal membrane staining of moderate intensity in at least $10 \%$ of cancer cells; strongly positive $(++)$, strong and complete membrane staining in at least $10 \%$ of cancer cells.

\section{Statistical Analysis}

Continuous variables such as age, tumor thickness and submucosal invasion thickness were analyzed after categorization.

Patients with cancer confined to the mucosa or with submucosal invasion thickness $<250 \mu \mathrm{m}$ had almost no risk of lymph node metastasis. We tried to look for useful variables in the cases with submucosal invasion thickness $\geq 250 \mu \mathrm{m}$ by statistical analysis. The $\chi^{2}$ test was utilized to analyze the differences in clinical, endoscopic and histopathological characteristics between the total cases and the cases with submucosal invasion thickness $\geq 250 \mu \mathrm{m}$, and between the cases with submucosal invasion thickness $\geq 250 \mu \mathrm{m}$ and the cases with submucosal invasion thickness $\geq 250 \mu \mathrm{m}$ which were included in the tissue microarrays. 
To evaluate the crude association between each clinicopathological, measured histopathological and immunohistochemical variable and the likelihood of having lymph node metastasis, we initially conducted univariate logistic regression analyses in both the total cases and the cases with submucosal invasion thickness $\geq 250 \mu \mathrm{m}$ which were included in the tissue microarrays. Significant predictors identified in the cases with complete data were assessed by backward stepwise multivariate logistic regression to assess the presence of possible confounding variables. Variables with a $P$-value of $<0.05$ were retained, and variables with a $P$-value of $>0.10$ were removed. Odds ratios and their $95 \%$ confidence intervals were calculated. Odds ratios may overestimate the true magnitude of the associations because the prevalence of lymph node metastasis was high $(20 \%)$ in the analyzed series of cases.

The capacity of the variables to differentiate the presence from the absence of lymph node metastasis was assessed with receiver operating characteristic curve analyses. The area under each receiver operating characteristic curve and its 95\% confidence intervals were calculated.

All statistics were performed using SPSS 16.0 for Windows (SPSS, Chicago, IL, USA), and twotailed $P$-values $<0.05$ were considered statistically significant.

\section{Results}

\section{Clinical Features and Endoscopic Parameters}

Clinical, endoscopic and histopathological features of the superficial esophageal squamous cell carcinoma cases are shown in Table 1 . The $\chi^{2}$ tests showed that the invasion depth level, tumor thickness, submucosal invasion thickness, the diameter of the largest invasive lesion and lymph node metastasis were significantly different between the total 271 cases and the 170 cases with submucosal invasion thickness $\geq 250 \mu \mathrm{m}$ which were included in the tissue microarrays. None of the variables were significantly different between the total 208 cases with submucosal invasion thickness $\geq 250 \mu \mathrm{m}$ and the 170 cases with submucosal invasion thickness $\geq 250 \mu \mathrm{m}$ which were included in the tissue microarrays. So the characteristics of the 170 cases can represent those of the 208 cases with submucosal invasion $\geq 250 \mu \mathrm{m}$, but cannot represent those of the total 271 cases.

\section{Macroscopic Tumor Types}

There were no occult type superficial esophageal squamous cell carcinomas. In all, 85 cases (31\%) were the erosive type, $32(12 \%)$ the papillary type, $120(44 \%)$ the plaque-like type, $15(6 \%)$ the ulcerative type and $19(7 \%)$ were the intraluminal mass type.

\section{Standard Histopathological Variables}

The maximum depth of invasion was $\mathrm{m} 2$ in 22 patients $(8 \%), \mathrm{m} 3$ in $30(11 \%), \mathrm{sm} 1$ in $23(9 \%), \mathrm{sm} 2$ in $55(20 \%)$ and sm3 in 141 patients (52\%).

In total, $49(18 \%)$ of the tumors were well differentiated, $104(38 \%)$ moderately differentiated, $80(30 \%)$ poorly differentiated, $25(9 \%)$ basaloid and $13(5 \%)$ spindle cell/sarcomatoid squamous cell carcinoma. Angiolymphatic invasion was observed in 51 cases $(19 \%)$. Glandular involvement by highgrade dysplasia/carcinoma-in-situ was observed in 73 cases $(27 \%)$.

\section{Measured Histopathological Variables}

Tumor thickness ranged from 325 to $80000 \mu \mathrm{m}$. Submucosal invasion thickness ranged from 0 to $10000 \mu \mathrm{m}$. The relationships between these measured variables, the maximum depth of invasion level, and lymph node metastasis are shown in Table 2. The diameters of the largest invasive lesion ranged from 0.1 to $7 \mathrm{~cm}$.

We tried different cut point values for the measured histopathological variables for statistical analysis. In all, $3000 \mu \mathrm{m}$ for tumor thickness, $2000 \mu \mathrm{m}$ for submucosal invasion thickness and $2 \mathrm{~cm}$ for the diameter of the largest invasive lesion were the best cut points for predicting lymph node metastasis.

\section{Immunohistochemical Results}

Representative immunohistochemical staining is shown in Figure 1, and the expression results for p53, cyclin D1, EGFR and VEGF are given in Table 1.

\section{Prevalence Rate of Lymph Node Metastasis}

In total, $53(20 \%)$ of the patients had at least one lymph node metastasis at surgery, including $2(4 \%)$ with tumors limited to the mucosa and 51 (23\%) with tumors invading the submucosa.

\section{Factors Predicting Lymph Node Metastasis}

The minimum value of tumor thickness in cases with lymph node metastasis was $1200 \mu \mathrm{m}$. In tumors limited to the mucosa, $0 / 22 \mathrm{~m} 2$ cases $(0 \%)$ and $2 / 30$ $\mathrm{m} 3$ cases $(7 \%)$ had lymph node metastasis; both $\mathrm{m} 3$ cases with lymph node metastasis had tumor thickness $>8000 \mu \mathrm{m}$. In tumors invading the submucosa, the minimum value of submucosal invasion thickness in cases with lymph node metastasis was $250 \mu \mathrm{m}$.

In univariate regression models, macroscopic tumor type, invasion depth level, degree of differentiation, angiolymphatic invasion, tumor thickness, submucosal invasion thickness and microscopic diameter of the largest invasive lesion 
Table 1 Summary of clinical, endoscopic and histopathological characteristics of the total 271 patients, and the total 208 patients with submucosal invasion thickness $\geq 250 \mu \mathrm{m}$, and the 170 tissue microarray patients with submucosal invasion thickness $\geq 250 \mu \mathrm{m}$

\begin{tabular}{|c|c|c|c|c|c|}
\hline Characteristics & $\begin{array}{c}\text { Total cases } \\
(\mathrm{n}=271), \text { no. }(\%)\end{array}$ & $\begin{array}{l}\text { Cases with submucosal } \\
\text { invasion thickness } \geq 250 \mu \mathrm{m} \\
(\mathrm{n}=208), \text { no. }(\%)\end{array}$ & $\begin{array}{l}\text { Tissue microarray cases with } \\
\text { submucosal invasion thickness } \\
\geq 250 \mu \mathrm{m}(\mathrm{n}=170), \text { no. }(\%)\end{array}$ & $\mathrm{P}^{\mathrm{a}}$ & $\mathrm{P}^{\mathrm{b}}$ \\
\hline \multicolumn{6}{|l|}{ Clinical variables } \\
\hline \multicolumn{6}{|l|}{ Sex } \\
\hline Male & $197(73)$ & $152(73)$ & $124(73)$ & 0.955 & 0.976 \\
\hline Female & $74(27)$ & $56(27)$ & $46(27)$ & & \\
\hline \multicolumn{6}{|l|}{ Age } \\
\hline$<60$ years & $167(62)$ & $127(61)$ & $106(62)$ & 0.878 & 0.797 \\
\hline$\geq 60$ years & $104(38)$ & $81(39)$ & $64(38)$ & & \\
\hline \multicolumn{6}{|l|}{ Symptoms } \\
\hline No symptoms & $14(5)$ & $8(4)$ & $5(3)$ & 0.263 & 0.631 \\
\hline Others & $257(95)$ & $200(96)$ & $165(97)$ & & \\
\hline \multicolumn{6}{|l|}{ Endoscopic variables } \\
\hline \multicolumn{6}{|l|}{$\begin{array}{l}\text { Tumor location } \\
\text { Tut }\end{array}$} \\
\hline Cervical & $2(1)$ & $2(1)$ & $2(1)$ & 0.756 & 0.995 \\
\hline Upper thoracic & $43(16)$ & 39 (18) & 33 (19) & & \\
\hline Middle thoracic & 187 (69) & $139(67)$ & $112(66)$ & & \\
\hline Lower thoracic & $39(14)$ & $28(14)$ & $23(14)$ & & \\
\hline \multicolumn{6}{|c|}{ Tumor size (measured endoscopically) } \\
\hline$<2 \mathrm{~cm}$ & $70(26)$ & 44 (21) & $37(22)$ & 0.332 & 0.886 \\
\hline$\geq 2 \mathrm{~cm}$ & $201(74)$ & $164(79)$ & $133(78)$ & & \\
\hline \multicolumn{6}{|l|}{ Macroscopic type } \\
\hline Erosive & $85(31)$ & $45(22)$ & $32(19)$ & 0.071 & 0.956 \\
\hline Papillary & $32(12)$ & $26(13)$ & $22(13)$ & & \\
\hline Plaque like & $120(44)$ & $106(51)$ & $92(54)$ & & \\
\hline Ulcerative & $15(6)$ & $14(7)$ & $10(6)$ & & \\
\hline Intraluminal mass & $19(7)$ & $17(8)$ & $14(8)$ & & \\
\hline \multicolumn{6}{|c|}{ Standard histopathological variables } \\
\hline \multicolumn{6}{|c|}{ Invasion depth level } \\
\hline $\mathrm{m} 2$ & $22(8)$ & NA & NA & $<0.001$ & 0.875 \\
\hline $\mathrm{m} 3$ & 30 (11) & NA & NA & & \\
\hline sm1 & $23(9)$ & $12(6)$ & $10(6)$ & & \\
\hline $\mathrm{sm} 2$ & $55(20)$ & $55(26)$ & $41(24)$ & & \\
\hline sm3 & $141(52)$ & $141(68)$ & $119(70)$ & & \\
\hline \multicolumn{6}{|c|}{ Degree of differentiation } \\
\hline Well & 49 (18) & $42(20)$ & $36(21)$ & 0.650 & 0.934 \\
\hline Moderate & $104(38)$ & $77(37)$ & $68(40)$ & & \\
\hline Poor & $80(30)$ & $57(27)$ & $40(24)$ & & \\
\hline Basaloid & $25(9)$ & $24(12)$ & 19 (11) & & \\
\hline Sarcomatoid & $13(5)$ & $8(4)$ & $7(4)$ & & \\
\hline \multicolumn{6}{|c|}{ Angiolymphatic invasion } \\
\hline No & $220(81)$ & $161(77)$ & $132(78)$ & 0.368 & 0.955 \\
\hline Yes & $51(19)$ & $47(23)$ & $38(22)$ & & \\
\hline \multicolumn{6}{|c|}{ Multicentric invasive lesions } \\
\hline No & $248(92)$ & $194(93)$ & $160(94)$ & 0.312 & 0.736 \\
\hline Yes & $23(8)$ & $14(7)$ & $10(6)$ & & \\
\hline \multicolumn{6}{|c|}{ Glandular involvement by high-grade dysplasia/carcinoma-in-situ } \\
\hline No & $198(73)$ & $156(75)$ & $129(76)$ & 0.510 & 0.843 \\
\hline Yes & $73(27)$ & $52(25)$ & $41(24)$ & & \\
\hline \multicolumn{6}{|c|}{ Measured histopathological variables } \\
\hline \multicolumn{6}{|c|}{ Tumor thickness } \\
\hline$<3000 \mu \mathrm{m}$ & $98(36)$ & $46(22)$ & $34(20)$ & $<0.001$ & 0.616 \\
\hline$\geq 3000 \mu \mathrm{m}$ & $173(64)$ & $162(78)$ & $136(80)$ & & \\
\hline \multicolumn{6}{|c|}{ Submucosal invasion thickness } \\
\hline$<2000 \mu \mathrm{m}$ & $156(58)$ & $93(45)$ & $71(42)$ & 0.005 & 0.565 \\
\hline$\geq 2000 \mu \mathrm{m}$ & $115(42)$ & $115(55)$ & $99(58)$ & & \\
\hline Diameter of largest in & ive lesion & & & & \\
\hline$<2 \mathrm{~cm}$ & $172(63)$ & $112(54)$ & $90(53)$ & 0.034 & 0.861 \\
\hline$\geq 2 \mathrm{~cm}$ & $99(37)$ & $96(46)$ & $80(47)$ & & \\
\hline
\end{tabular}


Table 1 Continued

\begin{tabular}{|c|c|c|c|c|c|}
\hline Characteristics & $\begin{array}{c}\text { Total cases } \\
(\mathrm{n}=271), \text { no. }(\%)\end{array}$ & $\begin{array}{c}\text { Cases with submucosal } \\
\text { invasion thickness } \geq 250 \mu \mathrm{m} \\
(\mathrm{n}=208), \text { no. }(\%)\end{array}$ & $\begin{array}{l}\text { Tissue microarray cases with } \\
\text { submucosal invasion thickness } \\
\geq 250 \mu \mathrm{m}(\mathrm{n}=170), \text { no. }(\%)\end{array}$ & $\mathrm{P}^{\mathrm{a}}$ & $\mathrm{P}^{\mathrm{b}}$ \\
\hline \multicolumn{6}{|c|}{ Lymph node metastasis } \\
\hline No & $218(80)$ & $157(75)$ & $123(72)$ & 0.048 & 0.490 \\
\hline Yes & $53(20)$ & $51(25)$ & $47(28)$ & & \\
\hline \multicolumn{6}{|c|}{ Immunohistochemial staining } \\
\hline $\begin{array}{r}\text { P53 } \\
-\end{array}$ & NA & NA & $76(46)$ & NA & NA \\
\hline+ & NA & NA & $41(25)$ & & \\
\hline++ & NA & NA & $47(29)$ & & \\
\hline \multicolumn{6}{|l|}{ Cyclin D1 } \\
\hline- & NA & NA & $51(31)$ & NA & NA \\
\hline+ & NA & NA & $47(29)$ & & \\
\hline++ & NA & NA & $64(40)$ & & \\
\hline \multicolumn{6}{|l|}{ EGFR } \\
\hline- & NA & NA & $59(36)$ & NA & NA \\
\hline+ & NA & NA & $53(32)$ & & \\
\hline++ & NA & NA & $52(32)$ & & \\
\hline \multicolumn{6}{|l|}{ VEGF } \\
\hline- & NA & NA & $51(31)$ & NA & NA \\
\hline+ & NA & NA & $45(28)$ & & \\
\hline++ & NA & NA & $66(41)$ & & \\
\hline
\end{tabular}

Abbreviation: NA, not associated.

${ }^{\mathrm{a}}$ Total 271 cases vs 170 tissue microarray submucosal cases with submucosal invasion thickness $\geq 250 \mu \mathrm{m}$.

$\mathrm{b}_{208}$ Submucosal cases with submucosal invasion thickness $\geq 250 \mu \mathrm{m}$ vs 170 tissue microarray submucosal cases with submucosal invasion thickness $\geq 250 \mu \mathrm{m}$.

Table 2 The relationships between tumor thickness and submucosal invasion thickness vs the depth of invasion level and the presence of lymph node metastasis in the total 271 patients

\begin{tabular}{|c|c|c|c|c|c|c|c|}
\hline Characteristics & Total & $m 2$ & m3 & sm1 & $s m 2$ & sm3 & $\begin{array}{l}\text { Lymph node } \\
\text { metastasis (\%) }\end{array}$ \\
\hline Total & 271 & 22 & 30 & 23 & 55 & 141 & $53(20)$ \\
\hline \multicolumn{8}{|l|}{ Tumor thickness } \\
\hline$<1000 \mu \mathrm{m}$ & 19 & 13 & 5 & 1 & 0 & 0 & $0(0)$ \\
\hline$\geq 1000$ and $<2000 \mu \mathrm{m}$ & 36 & 6 & 11 & 8 & 9 & 2 & $2(6)$ \\
\hline$\geq 2000$ and $<3000 \mu \mathrm{m}$ & 43 & 3 & 5 & 4 & 20 & 11 & $4(9)$ \\
\hline$\geq 3000$ and $<4000 \mu \mathrm{m}$ & 45 & 0 & 2 & 6 & 11 & 26 & $11(24)$ \\
\hline$\geq 4000$ and $<5000 \mu \mathrm{m}$ & 28 & 0 & 1 & 1 & 6 & 20 & $9(32)$ \\
\hline$\geq 5000$ and $<6000 \mu \mathrm{m}$ & 31 & 0 & 0 & 0 & 3 & 28 & $10(32)$ \\
\hline$\geq 6000$ and $<7000 \mu \mathrm{m}$ & 22 & 0 & 1 & 0 & 1 & 20 & $5(23)$ \\
\hline$\geq 7000$ and $<10000 \mu \mathrm{m}$ & 24 & 0 & 1 & 2 & 1 & 20 & $5(21)$ \\
\hline$\geq 10000 \mu \mathrm{m}$ & 23 & 0 & 4 & 1 & 4 & 14 & $7(30)$ \\
\hline \multicolumn{8}{|l|}{ Submucosal invasion thickness } \\
\hline Not beyond muscularis mucosae & 52 & 22 & 30 & 0 & 0 & 0 & $2(4)$ \\
\hline$<500 \mu \mathrm{m}$ & 20 & 0 & 0 & 16 & 4 & 0 & $2(10)$ \\
\hline$\geq 500$ and $<1000 \mu \mathrm{m}$ & 29 & 0 & 0 & 3 & 20 & 6 & $4(14)$ \\
\hline$\geq 1000$ and $<1500 \mu \mathrm{m}$ & 30 & 0 & 0 & 1 & 17 & 12 & $4(13)$ \\
\hline$\geq 1500$ and $<2000 \mu \mathrm{m}$ & 25 & 0 & 0 & 0 & 6 & 19 & $4(16)$ \\
\hline$\geq 2000$ and $<2500 \mu \mathrm{m}$ & 23 & 0 & 0 & 1 & 2 & 20 & $8(35)$ \\
\hline$\geq 2500$ and $<3000 \mu \mathrm{m}$ & 26 & 0 & 0 & 1 & 2 & 23 & $8(31)$ \\
\hline$\geq 3000$ and $<4000 \mu \mathrm{m}$ & 27 & 0 & 0 & 1 & 3 & 23 & $5(19)$ \\
\hline$\geq 4000$ and $<5000 \mu \mathrm{m}$ & 20 & 0 & 0 & 0 & 1 & 20 & $10(50)$ \\
\hline$\geq 5000 \mu \mathrm{m}$ & 19 & 0 & 0 & 0 & 0 & 19 & $6(32)$ \\
\hline Lymph node metastasis (\%) & & 0 & $2(7)$ & $4(17)$ & $7(13)$ & $40(28)$ & \\
\hline
\end{tabular}

were significantly related to lymph node metastasis in the total 271 cases $(P<0.05)$. Tumor size measured endoscopically was borderline significantly related to lymph node metastasis $(P=0.051)$. EGFR and VEGF were significantly related to lymph node metastasis in the tissue microarray cases (Table 3 ). 

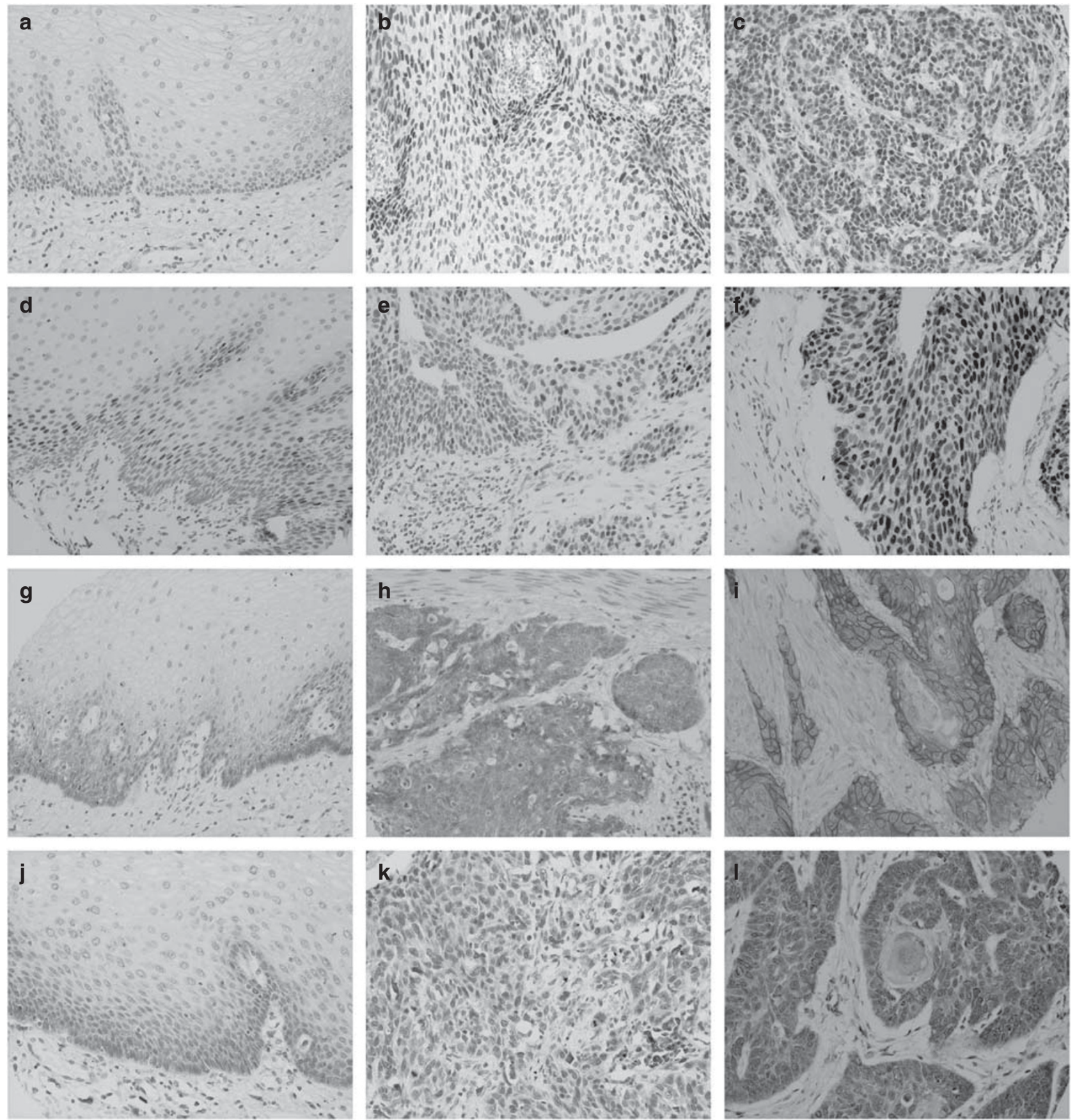

Figure 1 Representative photographs of immunohistochemical features of p53, cyclin D1, EGFR and VEGF in normal esophageal epithelia and superficial esophageal squamous cell carcinoma. P53 is negative in normal epithelia (a) and weakly (b) or strongly positive (c) in superficial esophageal squamous cell carcinoma. Cyclin D1 positivity is found only in the suprabasal cells of normal epithelia (d); it is weakly (e) or strongly (f) positive in superficial esophageal squamous cell carcinoma. EGFR staining can be very weak in the basal and suprabasal layers of normal epithelia (g); in superficial esophageal squamous cell carcinoma it is weakly (h) or strongly (i) positive, with the positive signal localized in the membrane of the cancer cells. VEGF staining can be very weak in the basal and suprabasal layers of normal epithelia (j); it is weakly (k) or strongly (l) positive in superficial esophageal squamous cell carcinoma (original magnification, $\times 200$ ).

After endoscopic examination and biopsies, but before endoscopic resection or esophagectomy, only some of these factors that predict lymph node metastasis can be evaluated. Macroscopic tumor type is known, and tumor size can be measured endoscopically, but the size and depth of the invasive part of the tumor cannot be determined. In addition, biopsies sample only small, superficial parts of the tumor, so the degree of differentiation, presence of angiolymphatic invasion, and EGFR and 
Table 3 Relationships between clinical and endoscopic variables, standard and measured histopathological variables, immunohistochemical staining and lymph node metastasis in the total 271 patients

\begin{tabular}{|c|c|c|c|c|c|c|}
\hline \multirow[t]{2}{*}{ Parameters } & \multirow[t]{2}{*}{ Total } & \multirow[t]{2}{*}{ Lymph node metastasis (\%) } & \multicolumn{4}{|c|}{ Univariate logistic regression } \\
\hline & & & Odds ratio & $95 \% C I$ & Global P & $\mathrm{P}$ - for-trend \\
\hline \multicolumn{7}{|l|}{ Clinical variables } \\
\hline \multicolumn{7}{|l|}{ Sex } \\
\hline Male & 197 & $43(22)$ & 1 & & & \\
\hline Female & 74 & $10(14)$ & 0.560 & $0.265-1.181$ & 0.128 & \\
\hline \multicolumn{7}{|l|}{ Age } \\
\hline$<60$ & 167 & $36(22)$ & 1 & & & \\
\hline$\geq 60$ & 104 & $17(16)$ & 0.711 & $0.376-1.345$ & 0.294 & \\
\hline \multicolumn{7}{|l|}{ Symptoms } \\
\hline No & 14 & 0 & 1 & & & \\
\hline Yes & 257 & $53(21)$ & $4.197 \times 10^{8}$ & $0-\infty$ & 0.999 & \\
\hline \multicolumn{7}{|l|}{ Endoscopic variables } \\
\hline \multicolumn{7}{|l|}{ Tumor location } \\
\hline Cervical & 2 & 0 & 0 & $0-\infty$ & 0.999 & \\
\hline Upper thoracic & 43 & 8 (19) & 0.993 & $0.424-2.326$ & 0.986 & \\
\hline Middle thoracic & 187 & 35 (19) & 1 & & & \\
\hline Lower thoracic & 39 & $10(26)$ & 1.498 & $0.668-3.357$ & 0.327 & \\
\hline \multicolumn{7}{|c|}{ Tumor size (measured endoscopically) } \\
\hline$<2 \mathrm{~cm}$ & 70 & $8(11)$ & 1 & & & \\
\hline$\geq 2 \mathrm{~cm}$ & 201 & $45(22)$ & 2.236 & $0.997-5.013$ & 0.051 & \\
\hline \multicolumn{7}{|l|}{ Macroscopic type } \\
\hline Erosive & 85 & $7(8)$ & 1 & & & \\
\hline Papillary & 32 & $4(13)$ & 1.592 & $0.433-5.853$ & 0.484 & \\
\hline Plaque like & 120 & $31(26)$ & 3.881 & $1.618-9.308$ & 0.002 & \\
\hline Ulcerative & 15 & $5(33)$ & 5.571 & $1.484-20.920$ & 0.011 & \\
\hline Intraluminal mass & 19 & $6(32)$ & 5.143 & $1.491-17.744$ & 0.010 & \\
\hline \multicolumn{7}{|c|}{ Standard histopathological variables } \\
\hline \multicolumn{7}{|c|}{ Invasion depth level } \\
\hline $\mathrm{m} 2$ & 22 & 0 & 1.903 & $1.334-2.716$ & & $<0.001$ \\
\hline m3 & 30 & $2(7)$ & & & & \\
\hline $\mathrm{sm} 1$ & 23 & $4(17)$ & & & & \\
\hline $\mathrm{sm} 2$ & 55 & $7(13)$ & & & & \\
\hline sm3 & 141 & $40(28)$ & & & & \\
\hline \multicolumn{7}{|c|}{ Degree of differentiation } \\
\hline Well & 49 & $4(8)$ & 1 & & & \\
\hline Moderate & 104 & $21(20)$ & 2.846 & 0.920-8.804 & 0.069 & \\
\hline Poor & 80 & $19(24)$ & 3.504 & $1.115-11.011$ & 0.032 & \\
\hline Basaloid & 25 & $5(20)$ & 2.812 & $0.682-11.593$ & 0.152 & \\
\hline Sarcomatoid & 13 & $4(31)$ & 5.000 & $1.051-23.789$ & 0.043 & \\
\hline \multicolumn{7}{|c|}{ Angiolymphatic invasion } \\
\hline No & 220 & $34(16)$ & 1 & & & \\
\hline Yes & 51 & $19(37)$ & 3.248 & $1.654-6.381$ & 0.001 & \\
\hline \multicolumn{7}{|c|}{ Multicentric invasive lesions } \\
\hline No & 248 & 47 (19) & 1 & & & \\
\hline Yes & 23 & $6(26)$ & 1.509 & $0.565-4.035$ & 0.412 & \\
\hline \multicolumn{7}{|c|}{ Glandular involvement by high-grade dysplasia/carcinoma-in-situ } \\
\hline No & 198 & $37(19)$ & 1 & & & \\
\hline Yes & 73 & $16(22)$ & 1.221 & $0.632-2.362$ & 0.552 & \\
\hline Measured histopatholc & l variab & & & & & \\
\hline Tumor thickness & & & & & & \\
\hline$<3000 \mu \mathrm{m}$ & 98 & $6(6)$ & 1 & & & \\
\hline$\geq 3000 \mu \mathrm{m}$ & 173 & $47(27)$ & 5.720 & $2.346-13.944$ & $<0.001$ & \\
\hline Submucosal invasio & ckness & & & & & \\
\hline$<1000 \mu \mathrm{m}$ & 101 & $8(8)$ & 1 & & & \\
\hline$\geq 1000 \mu \mathrm{m}$ & 170 & $45(26)$ & 4.107 & $1.848-9.128$ & $<0.001$ & \\
\hline
\end{tabular}


Table 3 Continued

\begin{tabular}{|c|c|c|c|c|c|c|}
\hline \multirow[t]{2}{*}{ Parameters } & \multirow[t]{2}{*}{ Total } & \multirow[t]{2}{*}{ Lymph node metastasis (\%) } & \multicolumn{4}{|c|}{ Univariate logistic regression } \\
\hline & & & Odds ratio & $95 \% C I$ & Global P & P-for-trend \\
\hline \multicolumn{7}{|c|}{ Diameter of the largest invasive lesion } \\
\hline$<2 \mathrm{~cm}$ & 172 & $27(16)$ & 1 & & & \\
\hline$\geq 2 \mathrm{~cm}$ & 99 & $26(26)$ & 1.913 & $1.042-3.512$ & 0.036 & \\
\hline \multicolumn{7}{|c|}{ Immunohistochemical staining $^{\mathrm{a}}$} \\
\hline \multicolumn{7}{|c|}{ P53 } \\
\hline- & 81 & $20(25)$ & 0.987 & $0.672-1.449$ & & 0.947 \\
\hline+ & 47 & $16(34)$ & & & & \\
\hline++ & 56 & $13(23)$ & & & & \\
\hline \multicolumn{7}{|l|}{ Cyclin D1 } \\
\hline- & 54 & $12(22)$ & 1.125 & $0.751-1.684$ & & 0.569 \\
\hline+ & 58 & $17(29)$ & & & & \\
\hline++ & 70 & $19(27)$ & & & & \\
\hline \multicolumn{7}{|l|}{ EGFR } \\
\hline- & 69 & $14(20)$ & 1.670 & $1.106-2.523$ & & 0.015 \\
\hline+ & 57 & $10(18)$ & & & & \\
\hline++ & 57 & $23(40)$ & & & & \\
\hline \multicolumn{7}{|l|}{ VEGF } \\
\hline- & 64 & $8(13)$ & 2.283 & $1.485-3.509$ & & $<0.001$ \\
\hline+ & 49 & $12(24)$ & & & & \\
\hline++ & 68 & $29(43)$ & & & & \\
\hline
\end{tabular}

Abbreviation: CI, confidence interval.

${ }^{a}$ Available in 196 tissue microarray cases.

VEGF expression may not be representative of the entire tumor. Thus, we think that the most important risk factors for lymph node metastasis before endoscopic resection are macroscopic tumor type and tumor size measured endoscopically. An algorithm for predicting lymph node metastasis before endoscopic resection is shown in Figure 2.

In the 170 tissue microarray cases with submucosal invasion thickness $\geq 250 \mu \mathrm{m}$, macroscopic tumor type, degree of differentiation and VEGF protein level were significantly related to lymph node metastasis $(P<0.05)$, and angiolymphatic invasion, submucosal invasion depth and EGFR protein level were borderline significantly related to lymph node metastasis ( $P=0.067,0.053$ and 0.060 , respectively). The univariate areas under receiver operating characteristic curves, in decreasing order, were $0.660,0.618$ and 0.617 for VEGF protein level, macroscopic tumor type and degree of differentiation, respectively (Table 4).

We assessed the presence of possible confounding variables in these 170 cases with multivariate logistic regression. The result showed that the most important risk factor for lymph node metastasis was VEGF protein level, followed by the degree of differentiation (Table 5). The area under receiver operating characteristic curve of combined VEGF and degree of differentiation was $0.722 \quad(95 \%$ confidence intervals, 0.641-0.804, $P<0.001$ ). An algorithm for predicting lymph node metastasis after endoscopic resection is shown in Figure 3.
Patients with cancer (1) thinner than $1200 \mu \mathrm{m}$; (2) confined to mucosa; (3) with submucosal invasion $<250 \mu \mathrm{m}$; (4) with submucosal invasion $\geq 250 \mu \mathrm{m}$ but with negative VEGF expression and well/ moderately differentiated or basaloid histology; or (5) with submucosal invasion $\geq 250 \mu \mathrm{m}$ but with weak VEGF expression and well-differentiated histolology had almost no risk of lymph node metastasis, so we think that they do not require additional treatment after endoscopic resection. Patients with submucosal invasion $\geq 250 \mu \mathrm{m}$ and (1) strong VEGF expression, (2) poorly differentiated or spindle cell histology or (3) weak VEGF expression and moderately differentiated or basaloid histology require additional treatment after endoscopic resection.

\section{Discussion}

We tried to identify clinical and histopathological parameters that could help determine which patients with superficial esophageal squamous cell carcinoma are good candidates for endoscopic resection treatment, and which need additional treatment after endoscopic resection. The characteristics available before endoscopic resection can be used to identify untreated patients who should go to endoscopic resection or esophagectomy. The characteristics available after endoscopic resection can be used to identify post-endoscopic resection patients who do or do not need additional treatment. 


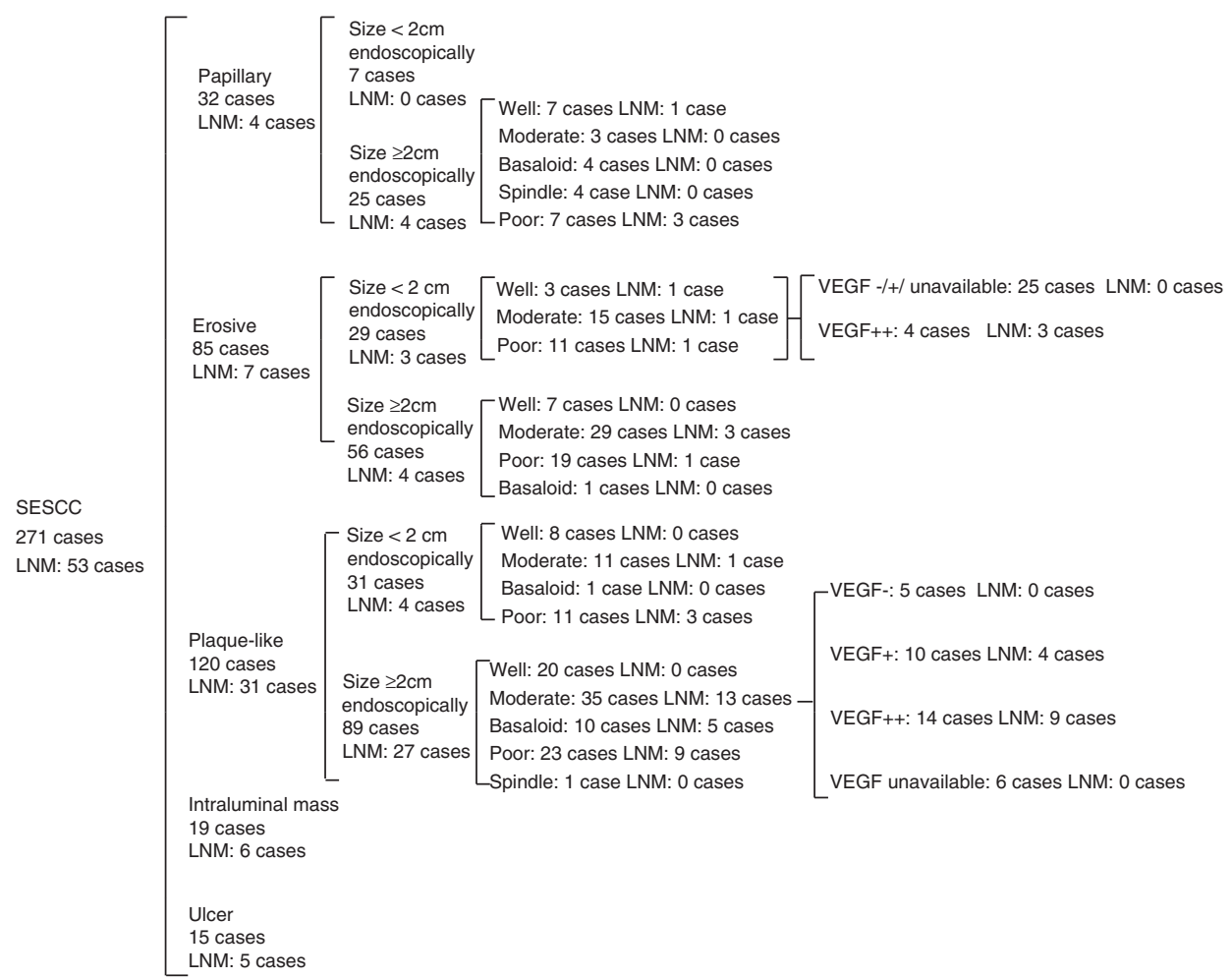

Figure 2 An algorithm for the prediction of lymph node metastasis before endoscopic resection. LNM, lymph node metastasis.

We grouped all variables by their availability in different settings, including clinical variables, endoscopic variables, standard histopathologic variables, measured histopathologic variables and immunohistochemical staining (Table 1).

It has been reported that macroscopic shape correlates with invasion depth and lymph node metastasis, and patients with non-flat shapes have a higher frequency of metastasis..$^{5,8,9,14}$ Our data are consistent with these reports. Patients with intraluminal masses and ulcerated tumors had much more frequent lymph node metastasis. But multivariate analysis in the 170 tissue microarray cases with submucosal invasion thickness $\geq 250 \mu \mathrm{m}$ showed that macroscopic tumor type was not an independent predictor, and was less important than degree of histologic differentiation and VEGF expression level. So macroscopic tumor type is more valuable for determining candidates for endoscopic resection than for determining the need for additional treatment after endoscopic resection.

No m2 cases had lymph node metastasis, and only two m3 cases had lymph node metastasis in our study. Both of these two cases had tumor thickness $>8000 \mu \mathrm{m}$. So no cases with mucosal tumors with tumor thickness $<8000 \mu$ m had lymph node metastasis. We measured both tumor thickness and submucosal invasion thickness and investigated whether tumor thickness and submucosal invasion thickness reflected lymph node metastasis. As tumor thickness and submucosal invasion thickness increased, the frequency of lymph node metastasis increased (Table 2). The minimum value of tumor thickness in cases with lymph node metastasis was $1200 \mu \mathrm{m}$, so in our experience, patients with tumor thickness $<1200 \mu \mathrm{m}$ have essentially no risk of metastasis. The minimum value of submucosal invasion thickness in submucosal cases with lymph node metastasis was $250 \mu \mathrm{m}$, so in our experience, patients with submucosal invasion thickness $<250 \mu$ m have almost no risk of metastasis, which was similar to the results of Tajima et al. ${ }^{11}$ So we think that additional surgical resection after endoscopic resection is probably not required for patients with total tumor thickness $<1200 \mu \mathrm{m}$, in tumors limited to the mucosa, or in cases with submucosal invasion $<250 \mu \mathrm{m}$, no matter what the other parameters show.

Previous studies reported that lymph node involvement was frequently found when the tumor size was $>2 \mathrm{~cm} .{ }^{8,12}$ These authors did not mention how they measured tumor size, grossly (by endoscopic measurement or by pathologic measurement of resection specimens) or microscopically. In this study, we measured the size of the largest invasive lesion microscopically, and used a $2 \mathrm{~cm}$ cutoff value for analysis. In this analysis, larger tumor size was significantly related to lymph node metastasis in the total 271 patients, but was not an independent predictor. We also measured the tumor size endoscopically, and found that it was only borderline significantly related with lymph node metastasis, possibly because the tumor size measured 
Table 4 Relationships between clinical and endoscopic variables, standard and measured histopathological variables, immunohistochemical results and lymph node metastasis in the 170 tissue microarray cases with submucosal invasion thickness $\geq 250 \mu$ m

\begin{tabular}{|c|c|c|c|c|c|c|c|c|c|}
\hline \multirow[t]{2}{*}{ Parameters } & \multirow[t]{2}{*}{ Total } & \multirow[t]{2}{*}{$\begin{array}{l}\text { Lymph node } \\
\text { metastasis (\%) }\end{array}$} & \multicolumn{4}{|c|}{$\begin{array}{l}\text { Univariate logistic } \\
\text { regression }\end{array}$} & \multicolumn{3}{|c|}{$\begin{array}{l}\text { Receiver operating } \\
\text { characteristic curve }\end{array}$} \\
\hline & & & Odds ratio & $95 \% C I$ & Global P & $\begin{array}{c}\mathrm{P}- \\
\text { for-trend }\end{array}$ & $\begin{array}{l}\text { Area under } \\
\text { the curve }\end{array}$ & $95 \% C I$ & $\mathrm{P}$ \\
\hline \multicolumn{10}{|l|}{ Clinical variables } \\
\hline \multicolumn{10}{|l|}{ Sex } \\
\hline Male & 124 & $38(31)$ & 1 & & & & 0.555 & $0.460-0.649$ & 0.271 \\
\hline Female & 46 & $9(20)$ & 0.550 & $0.242-1.253$ & 0.155 & & & & \\
\hline \multicolumn{10}{|l|}{ Age } \\
\hline$<60$ & 106 & $32(30)$ & 1 & & & & 0.540 & $0.444-0.636$ & 0.425 \\
\hline$\geq 60$ & 64 & $15(23)$ & 0.708 & $0.347-1.442$ & 0.341 & & & & \\
\hline \multicolumn{10}{|l|}{ Symptoms } \\
\hline No & 5 & 0 & 1 & & & & 0.520 & $0.425-0.616$ & 0.682 \\
\hline Yes & 165 & $47(28)$ & $6.435 \times 10^{8}$ & $0-\infty$ & 0.999 & & & & \\
\hline \multicolumn{10}{|l|}{ Endoscopic variables } \\
\hline \multicolumn{10}{|l|}{ Tumor location } \\
\hline Cervical & 2 & 0 & 0 & $0-\infty$ & 0.999 & & 0.578 & $0.481-0.675$ & 0.117 \\
\hline Upper thoracic & 33 & $7(21)$ & 0.736 & $0.289-1.872$ & 0.520 & & & & \\
\hline Middle thoracic & 112 & $30(27)$ & 1 & & & & & & \\
\hline Lower thoracic & 23 & $10(43)$ & 2.103 & $0.834-5.299$ & 0.115 & & & & \\
\hline \multicolumn{10}{|c|}{ Tumor size (measured endoscopically) } \\
\hline$<2 \mathrm{~cm}$ & 37 & $8(22)$ & 1 & & & & 0.533 & $0.437-0.628$ & 0.509 \\
\hline$\geq 2 \mathrm{~cm}$ & 133 & $39(29)$ & 1.504 & $0.632-3.580$ & 0.356 & & & & \\
\hline \multicolumn{10}{|l|}{ Macroscopic type } \\
\hline Papillary & 22 & $2(9)$ & 1 & & & & 0.618 & $0.527-0.710$ & 0.017 \\
\hline Erosive & 32 & $7(22)$ & 2.800 & $0.523-14.992$ & 0.229 & & & & \\
\hline Plaque like & 92 & $28(30)$ & 4.375 & $0.957-20.001$ & 0.057 & & & & \\
\hline Ulcerative & 10 & $5(50)$ & 10.000 & $1.480-67.554$ & 0.018 & & & & \\
\hline Intraluminal mass & 14 & $5(36)$ & 5.556 & $0.901-34.246$ & 0.065 & & & & \\
\hline \multicolumn{10}{|c|}{ Standard histopathological variables } \\
\hline \multicolumn{10}{|c|}{ Invasion depth level } \\
\hline $\operatorname{sm} 1$ & 10 & $3(30)$ & 1.423 & $0.766-2.646$ & & 0.264 & 0.556 & $0.460-0.651$ & 0.262 \\
\hline $\mathrm{sm} 2$ & 41 & $7(17)$ & & & & & & & \\
\hline sm3 & 119 & $37(31)$ & & & & & & & \\
\hline \multicolumn{10}{|c|}{ Degree of differentiation } \\
\hline Well & 36 & $4(11)$ & 1 & & & & 0.617 & $0.526-0.707$ & 0.019 \\
\hline Moderate & 68 & $21(31)$ & 3.574 & $1.121-11.400$ & 0.031 & & & & \\
\hline Poor & 40 & $14(35)$ & 4.308 & $1.264-14.676$ & 0.020 & & & & \\
\hline Basaloid & 19 & $5(26)$ & 2.857 & $0.665-12.267$ & 0.158 & & & & \\
\hline Sarcomatoid & 7 & $3(43)$ & 6.000 & $0.970-37.121$ & 0.054 & & & & \\
\hline \multicolumn{10}{|c|}{ Angiolymphatic invasion } \\
\hline No & 132 & $32(24)$ & 1 & & & & 0.566 & $0.467-0.665$ & 0.183 \\
\hline Yes & 38 & $15(39)$ & 2.038 & $0.951-4.369$ & 0.067 & & & & \\
\hline Multicentric invasive & lesions & & & & & & & & \\
\hline No & 160 & $39(24)$ & 1 & & & & 0.518 & $0.420-0.617$ & 0.714 \\
\hline Yes & 10 & $8(80)$ & 1.814 & $0.488-6.740$ & 0.374 & & & & \\
\hline Glandular involveme & at by hi & gh-grade dysplas & a/carcinoma- & in-situ & & & & & \\
\hline No & 129 & $33(26)$ & 1 & & & & 0.539 & $0.441-0.638$ & 0.430 \\
\hline Yes & 41 & $14(34)$ & 1.508 & $0.708-3.216$ & 0.287 & & & & \\
\hline Measured histopatholo & ical var & riables & & & & & & & \\
\hline Tumor thickness & & & & & & & & & \\
\hline$<3000 \mu \mathrm{m}$ & 34 & 6 (18) & 1 & & & & 0.550 & $0.456-0.644$ & 0.314 \\
\hline$\geq 3000 \mu \mathrm{m}$ & 136 & $41(30)$ & 2.014 & $0.775-5.233$ & 0.151 & & & & \\
\hline Submucosal invasion & thickne & & & & & & & & \\
\hline$<2000 \mu \mathrm{m}$ & 71 & $14(20)$ & 1 & & & & 0.583 & $0.489-0.677$ & 0.095 \\
\hline$\geq 2000 \mu \mathrm{m}$ & 99 & $33(33)$ & 2.036 & $0.992-4.176$ & 0.053 & & & & \\
\hline
\end{tabular}


Table 4 Continued

\begin{tabular}{|c|c|c|c|c|c|c|c|c|c|}
\hline \multirow[t]{2}{*}{ Parameters } & \multirow[t]{2}{*}{ Total } & \multirow[t]{2}{*}{$\begin{array}{l}\text { Lymph node } \\
\text { metastasis (\%) }\end{array}$} & \multicolumn{4}{|c|}{$\begin{array}{l}\text { Univariate logistic } \\
\text { regression }\end{array}$} & \multicolumn{3}{|c|}{$\begin{array}{l}\text { Receiver operating } \\
\text { characteristic curve }\end{array}$} \\
\hline & & & Odds ratio & $95 \% C I$ & Global P & $\begin{array}{c}\mathrm{P}- \\
\text { for-trend }\end{array}$ & $\begin{array}{l}\text { Area under } \\
\text { the curve }\end{array}$ & $95 \% C I$ & $\mathrm{P}$ \\
\hline \multicolumn{10}{|c|}{ Diameter of the largest invasive lesion } \\
\hline$<2 \mathrm{~cm}$ & 90 & $25(28)$ & 1 & & & & 0.508 & $0.411-0.606$ & 0.867 \\
\hline$\geq 2 \mathrm{~cm}$ & 80 & $22(28)$ & 0.935 & $0.476-1.838$ & 0.846 & & & & \\
\hline \multicolumn{10}{|c|}{ Immunohistochemical staining } \\
\hline \multicolumn{10}{|c|}{ P53 } \\
\hline- & 76 & $19(25)$ & 1.100 & $0.739-1.637$ & & 0.638 & 0.526 & $0.430-0.622$ & 0.606 \\
\hline+ & 41 & $15(37)$ & & & & & & & \\
\hline++ & 47 & $13(28)$ & & & & & & & \\
\hline \multicolumn{10}{|l|}{ Cyclin D1 } \\
\hline- & 51 & $12(24)$ & 1.155 & $0.766-1.740$ & & 0.492 & 0.531 & $0.434-0.628$ & 0.534 \\
\hline+ & 47 & $15(32)$ & & & & & & & \\
\hline++ & 64 & $19(30)$ & & & & & & & \\
\hline \multicolumn{10}{|l|}{ EGFR } \\
\hline - & 59 & $14(24)$ & 1.506 & $0.984-2.304$ & & 0.060 & 0.589 & $0.487-0.691$ & 0.079 \\
\hline+ & 53 & $10(19)$ & & & & & & & \\
\hline++ & 52 & $21(40)$ & & & & & & & \\
\hline \multicolumn{10}{|l|}{ VEGF } \\
\hline- & 51 & 7 (14) & 2.133 & $1.362-3.340$ & & 0.001 & 0.660 & $0.570-0.750$ & 0.001 \\
\hline+ & 45 & $12(27)$ & & & & & & & \\
\hline++ & 66 & $28(42)$ & & & & & & & \\
\hline
\end{tabular}

Abbreviation: CI, confidence interval.

endoscopically usually includes areas of precursor lesions, which often accompany invasive lesions, so this measurement is not as accurate as the invasive size measured microscopically.

In our study, degree of differentiation was related with lymph node metastasis, similar to the results of Eguchi et $a l^{7}$ and Tajima et $a .^{11}$

Angiolymphatic invasion was also related to lymph node metastasis in the total 271 patients, consistent with previous studies. ${ }^{6,7,10,11}$ But it was only borderline significantly related with lymph node metastasis $(P=0.067)$ in the 170 tissue microarray cases with submucosal invasion thickness $\geq 250 \mu \mathrm{m}$.

In univariate analyses of the total 271 cases, both EGFR and VEGF were significantly correlated with lymph node metastasis. In multivariate analysis, VEGF was the most important independent predictor of lymph node metastasis in the 170 tissue microarray cases with submucosal invasion thickness $\geq 250 \mu \mathrm{m}$. If a patient's tumor has strong VEGF expression, he probably requires additional treatment after endoscopic resection.

For tumors with submucosal invasion deeper than $250 \mu \mathrm{m}$, we found that those with negative VEGF expression and well or moderately differentiated or basaloid histology, and those with weak VEGF expression and well-differentiated histology had almost no risk of lymph node metastasis, so we think that such patients do not require additional treatment after endoscopic resection. Previous
Table 5 Multivariate logistic regression analysis for lymph node metastasis in the 170 tissue microarray cases with submucosal cancer and submucosal invasion thickness $\geq 250 \mu \mathrm{m}$

\begin{tabular}{lcccc}
\hline Parameters & Odds ratio & $95 \%$ CI & Global P $\begin{array}{c}\text { P- } \\
\text { for-trend }\end{array}$ \\
\hline Macroscopic shapes & & & & \\
$\quad$ Erosive & & & 0.286 & \\
$\quad$ Papillary & 1 & & & \\
$\quad$ Plaque like & & & 0.474 & \\
$\quad$ Ulcerative & & & 0.161 & \\
$\quad$ Intraluminal mass & & & 0.490 & \\
\multicolumn{1}{l}{ Degree of differentiation } & & & & \\
$\quad$ Well & 1 & & & \\
$\quad$ Moderate & 2.708 & $0.816-8.984$ & 0.104 & \\
$\quad$ Poor & 4.425 & $1.247-12.704$ & 0.021 & \\
$\quad$ Basaloid & 2.651 & $0.587-11.976$ & 0.205 & \\
$\quad$ Sarcomatoid & 12.352 & $1.415-107.864$ & 0.023 & \\
VEGF level & 2.119 & $1.319-3.405$ & & 0.002 \\
& & &
\end{tabular}

Abbreviation: CI, confidence interval.

guidelines have suggested that all endoscopic resection patients with submucosal invasion deeper than $200 \mu \mathrm{m}$ should undergo additional treatment. ${ }^{22}$ In the current series, 42 of the 162 VEGF informative cases could have avoided esophagectomy using our new treatment algorithm (Figure 3).

In conclusion, we recommend endoscopic ultrasonography and CT of the chest and abdomen with contrast for all patients who have biopsy-proven 


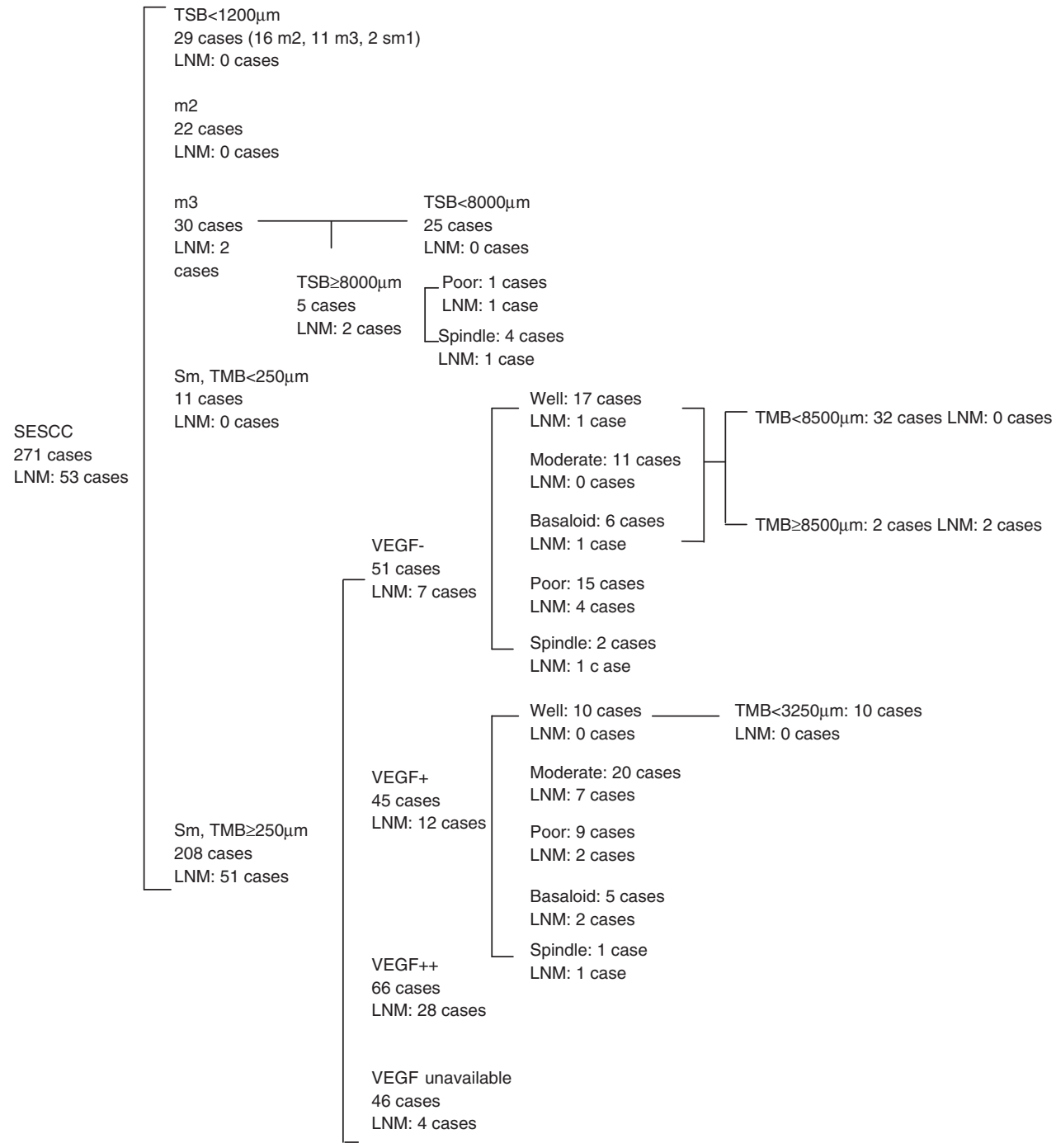

Figure 3 An algorithm for the prediction of lymph node metastasis after endoscopic resection. LNM, lymph node metastasis; TMB, submucosal invasion thickness from the bottom of muscularis mucosae to the base of cancer nests; TSB, tumor thickness from the surface to the base of cancer nests.

invasive esophageal squamous cell carcinoma; and in those who are endoscopic ultrasonography and CT negative, we recommend:

(1) Endoscopic resection on all erosive, papillary and plaque-like cases where endoscopic resection is clinically feasible (if the lesion is $<6 \mathrm{~cm}$ long and $<3 / 4$ of the circumference in our hospital).

(2) Esophagectomy on all other erosive, papillary and plaque-like cases and on all intraluminal masses and ulcerated tumors.

(3) No additional treatment on endoscopic resection cases with tumor thickness $<1200 \mu \mathrm{m}$, tumors limited to the mucosa and tumors invading the submucosa $<250 \mu \mathrm{m}$.

In patients with tumors invading the submucosa $\geq 250 \mu \mathrm{m}$, the most important criteria for deciding whether or not to recommend additional treatment are VEGF staining and tumor histology. If VEGF is negative and the tumor is well differentiated, moderately differentiated or shows basaloid histology, or if VEGF is weakly positive and the tumor is well differentiated, then close patient follow-up without additional treatment appears reasonable; but if VEGF is strongly positive or if the tumor is poorly differentiated or shows spindled histology, then additional therapy is recommended.

\section{Acknowledgements}

The work was supported by grants from the National Natural Science Foundation of the Peoples' Republic of China (No. 30271460, 30670964 and 30770973) and the Beijing Hope Run Special Fund (No. LC2007B51), and was also supported in part by the Intramural Research Program of the Division of Cancer Epidemiology and Genetics of the National Cancer Institute, NIH. 


\section{Disclosure/conflict of interest}

The authors declare no conflict of interest.

\section{References}

1 Shimizu Y, Tsukagoshi H, Fujita M, et al. Long-term outcome after endoscopic mucosal resection in patients with esophageal squamous cell carcinoma invading the muscularis mucosae or deeper. Gastrointest Endosc 2002;56:387-390.

2 Ishihara R, Tanaka H, Iishi $\mathrm{H}$, et al. Long-term outcome of esophageal mucosal squamous cell carcinoma without lymphovascular involvement after endoscopic resection. Cancer 2008;112:2166-2172.

3 Ishihara R, Iishi H, Uedo N, et al. Comparison of EMR and endoscopic submucosal dissection for en bloc resection of early esophageal cancers in Japan. Gastrointest Endosc 2008;68:1066-1072.

4 Peters FP, Kara MA, Curvers WL, et al. Multiband mucosectomy for endoscopic resection of Barrett's esophagus: feasibility study with matched historical controls. Eur J Gastroenterol Hepatol 2007;19:311-315.

5 Shimada H, Nabeya Y, Matsubara H, et al. Prediction of lymph node status in patients with superficial esophageal carcinoma: analysis of 160 surgically resected cancers. Am J Surg 2006;191:250-254.

6 Ancona E, Rampado S, Cassaro M, et al. Prediction of lymph node status in superficial esophageal carcinoma. Ann Surg Oncol 2008;15:3278-3288.

7 Eguchi T, Nakanishi Y, Shimoda T, et al. Histopathological criteria for additional treatment after endoscopic mucosal resection for esophageal cancer: analysis of 464 surgically resected cases. Mod Pathol 2006;19:475-480.

8 Kim DU, Lee JH, Min BH, et al. Risk factors of lymph node metastasis in T1 esophageal squamous cell carcinoma. J Gastroenterol Hepatol 2008;23:619-625.

9 Nagawa H, Kaizaki S, Seto Y, et al. The relationship of macroscopic shape of superficial esophageal carcinoma to depth of invasion and regional lymph node metastasis. Cancer 1995;75:1061-1064.

10 Nakajima Y, Nagai K, Miyake S, et al. Evaluation of an indicator for lymph node metastasis of esophageal squamous cell carcinoma invading the submucosal layer. Jpn J Cancer Res 2002;93:305-312.

11 Tajima Y, Nakanishi Y, Ochiai A, et al. Histopathologic findings predicting lymph node metastasis and prognosis of patients with superficial esophageal carcinoma: analysis of 240 surgically resected tumors. Cancer 2000;88:1285-1293.

12 Tachibana M, Hirahara N, Kinugasa S, et al. Clinicopathologic features of superficial esophageal cancer: results of consecutive 100 patients. Ann Surg Oncol 2008;15:104-116.

13 Matsubara T, Ueda M, Abe T, et al. Unique distribution patterns of metastatic lymph nodes in patients with superficial carcinoma of the thoracic oesophagus. Br J Surg 1999;86:669-673.

14 Ohno S, Mori M, Tsutsui S, et al. Growth patterns and prognosis of submucosal carcinoma of the esophagus. A pathologic study. Cancer 1991;68:335-340.

15 Endo M, Yoshino K, Kawano T, et al. Clinicopathologic analysis of lymph node metastasis in surgically resected superficial cancer of the thoracic esophagus. Dis Esophagus 2000;13:125-129.

16 Bogomoletz WV, Molas G, Gayet B, et al. Superficial squamous cell carcinoma of the esophagus. A report of 76 cases and review of the literature. Am J Surg Pathol 1989;13:535-546.

17 Wang GQ, Jiao GG, Chang FB, et al. Long-term results of operation for 420 patients with early squamous cell esophageal carcinoma discovered by screening. Ann Thorac Surg 2004;77:1740-1744.

18 Schlemper RJ, Dawsey SM, Itabashi M, et al. Differences in diagnostic criteria for esophageal squamous cell carcinoma between Japanese and Western pathologists. Cancer 2000;88:996-1006.

19 Jass JR. Discrepancies between East and West. Cancer 2000;88:969-970.

20 Liu F, Li L, Qu S. Clinical and pathological characteristics of early oesophageal cancer. Clin Oncol 1982;1:539-557.

21 Barge J, Molas G, Maillard JN, et al. Superficial oesophageal carcinoma: an oesophageal counterpart of early gastric cancer. Histopathology 1981;5: 499-510.

22 Endoscopic Classification Review Group. Update on the Paris classification of superficial neoplastic lesions in the digestive tract. Endoscopy 2005;37: 570-578.

23 Hamilton SR, Aaltonen LA. Chapter 1, tumours of the oesophagus. In: Hamilton SR, Aaltonen LA (eds). World Health Organization Classification of Tumours. Pathology and Genetics of Tumours of the Digestive System. IARC Press: Lyon, 2000, pp 14-16.

24 Hao XP, Pretlow TG, Rao JS, et al. Beta-catenin expression is altered in human colonic aberrant crypt foci. Cancer Res 2001;61:8085-8088. 